\title{
Applying Fuzzy Multiobjective Integrated Logistics Model to Green Supply Chain Problems
}

\author{
Chui-Yu Chiu, ${ }^{1}$ Yi Lin, ${ }^{2}$ and Ming-Feng Yang ${ }^{3}$ \\ ${ }^{1}$ Department of Industrial Engineering and Management, National Taipei University of Technology, No. 1, Section 3, \\ Chung-Hsiao East Road, Taipei 10643, Taiwan \\ ${ }^{2}$ College of Management, National Taipei University of Technology, No. 1, Section 3, Chung-Hsiao East Road, Taipei 10643, Taiwan \\ ${ }^{3}$ Department of Transportation Science, National Taiwan Ocean University, Keelung City 202, Taiwan
}

Correspondence should be addressed to Yi Lin; iwc3706@yahoo.com.tw

Received 19 January 2014; Revised 12 June 2014; Accepted 13 June 2014; Published 7 July 2014

Academic Editor: Ricardo Perera

Copyright (C) 2014 Chui-Yu Chiu et al. This is an open access article distributed under the Creative Commons Attribution License, which permits unrestricted use, distribution, and reproduction in any medium, provided the original work is properly cited.

\begin{abstract}
The aim of this paper is attempting to explore the optimal way of supply chain management within the domain of environmental responsibility and concerns. The background of this research involves the issue of green supply chain management (GSCM) and the concept of the multiobjective integrated logistics model. More specifically, in this paper, we suggest the fuzzy multiobjective integrated logistics model with the transportation cost and demand fuzziness to solve green supply chain problems in the uncertain environment which is illustrated via the detailed numerical example. Results and the sensitivity analysis of the numerical example indicate that when the governmental subsidy value increased the profits of the reverse chain also increased. The finding shows that the governmental subsidy policy could remain of significant influence for used-product reverse logistics chain.
\end{abstract}

\section{Introduction}

In today's highly competitive global market, preferable environmental concerns and reserved considerations are acknowledged as having high potential to impact the benefits of the supply chain management. Both academicians and practitioners tend to find an optimal way to keep business competition with more environmental concerns. Hence, the manufacturers have to consider carefully many aspects that govern their performance in order to ensure end user satisfaction [1]. In recent years considerable concern has been arising over the issues of environmental pollution accompanying industrial development in the operational process of the supply chain management research. Environment protection is becoming a vital issue for enterprises, government, and nonprofit organizations because of stronger public awareness. Indeed, the green supply chain management has emerged as an approach to balance these competitive requirements [2].

This paper is an attempt to fill the gap in the existing literature of GSCM, much of which focuses on the manufacturing chain, reverse logistics chain, chain members, cash flow, and so forth. However, major issues of uncertainty and real-world applications have not been many researches attentions. In view of this gap, we consider the fuzzy demand and transportation cost more closely in the real-world situation.

\section{Literature Review}

In reality, the environment of global market is complicated and uncertain; therefore, some researchers have been devoting themselves to research the supply chain management with the aspect of uncertainty. Petrovic et al. [3] applied fuzzy set to handle uncertain demands and external raw material problems and to deal with linguistic expressions and uncertain issues. Giannoccaro et al. [4] also proposed fuzzy sets theory to the uncertainties associated with both market demand and inventory costs. In this paper, center of gravity is proposed to convert the fuzzy number into a crisp number.

As a result of increasing challenges in highly competitive global supply chain environment, both academicians and practitioners have increasing interests of finding the optimal way to remain competitive, and manufacturers have also been seeking to deliver to their customers high-quality products in the right time at the right price [1]. Drzymalski and Odrey [5] 
proposed that each entity within a supply chain is also different in its constraints, operations, and objectives, resulting in varying performance measures within each organization. Hence, supply chain modeling has been becoming crucial as companies face more complicated and global interactions and increased customer expectations. When an item moves through more than one step before reaching the final customer, the terms "multilevel" or "multiechelon" production and distribution supply chain are also synonymous with such supply chains [6-8]. Initial multiechelon inventory theory was introduced by Clark and Scarf [9] as a way of proving the optimality of a base stock policy for the pure serial inventory system and developed an efficient decomposing method to compute the optimal base stock ordering policy. In addition, some researchers considered a strategic supply chain design problem with three echelons, multiple commodities, and technology selection [10]. And then, Disney et al. [11] proposed the research on a coordination scheme in a twoechelon supply chain which involves sharing details of lead times, replenishment rules, and demand patterns and tuning the replenishment rules to exploit the supply chain's cost structure. Yazlali and Erhun [12] noted a single-product dualsupply problem under a periodically reviewed, finite planning horizon. As we mentioned in the earlier section, with the promotion of environmental consciousness in recent years, the logistics and supply chain managers have to balance efforts to reduce costs and innovate while maintaining good environmental (ecological) performance [13]. The enterprises also have to take more applicable measures to improve reverse logistics. Indeed, the green supply chain management (GSCM) has appeared as an approach to balance these competitive requirements [2].

Recently, greening the supply chain has become the vital issue. Many organizations, universities, and governments held conferences of supply chain management with environmental thinking. The purpose of these conferences was to demonstrate and exchange the green technology, green knowledge, and green research. It means that the field of green supply chain management has been becoming more and more important in both academic research and practice in the real market [14]. Also, there have been a number of studies that have developed and implemented how to green the supply chain. For example, Hsu et al. [15] applied the Decision-Making Trial and Evaluation Laboratory (DEMATEL) approach to select the green suppliers in green supply chain management. Pishvaee et al. [16] created the model to minimize the environmental impacts and costs in the green supply chain. And then, Trappey et al. [17] designed the green production planning and discussed how to minimize a product's carbon footprint.

However, due to the imprecision of the information related to parameters, the deterministic models are inappropriate for obtaining an effective solution for supply chain implications. In uncertainty, the method to carry out this study is applying the fuzzy set theory, which provides a way to obtain feasible answers to overcome the natural difficulties. There have been a number of studies that have investigated the implications of the fuzzy set theory. The fuzzy decision-making concept, introduced by Bellman and Zadeh [18] as a way of handling imprecise data, proposed the most suitable fuzzy decision analysis procedure in the fuzzy environment. Afterwards, Zimmermann [19] combined the fuzzy sets theory, the traditional linear programming, and the fuzzy decision-making and linear membership function as the modified method and it became a new academic direction.

In fuzzy multiobjective programming aspect, the paper by Zimmermann [20] provided the fuzzy goals of the decisionmaker with the fuzzy decisions. Bellman and Zadeh [18] noted in their research that the linear membership functions and the fuzzy decisions can be adopted to convert the problem to be solved into an ordinary single-goal mathematical programming (Max $L$ ) problem. Then, Li et al. [21] and Kumar et al. [22] developed a fuzzy mixed integer goal programming approach for supplier evaluation and selection model. Furthermore, Kumar et al. [23] and Amid et al. [24] extended their research and developed a fuzzy multiobjective integer programming model to deal with the different weights in various criteria. Numerous studies noted that the fuzzy multiobjective programming decision models remained consistently under different situations [2528].

\section{Model Formulation}

The purpose of this section is to establish a mathematical model. In this work, we modified the integrated logistics model which is indicated by Sheu et al. [29]. We use the linear multiobjective programming model into the integrated logistics operational problems of green supply chain management. The objective of our proposed model is to maximize the total profit function with respect to general manufacturing chain and the reverse chain. Also, we consider the fuzzy demand and transportation cost and adopt the triangular fuzzy number to represent these variables [29].

3.1. Assumptions. The assumptions of this research are as follows.

(1) Only single product is considered in the proposed model.

(2) The time-varying quantity of product demands from end customers in any given time interval is given.

(3) Shortages are not allowed.

(4) There is a given return ratio, referring to the proportion of the quantity of used products returned from end customers and through the reverse logistics chain.

(5) The time horizon is infinite.

(6) Facility capacities associated with chain members of the proposed integrated logistics system are known.

(7) The lead time is known in both the general and the reverse supply chains. 


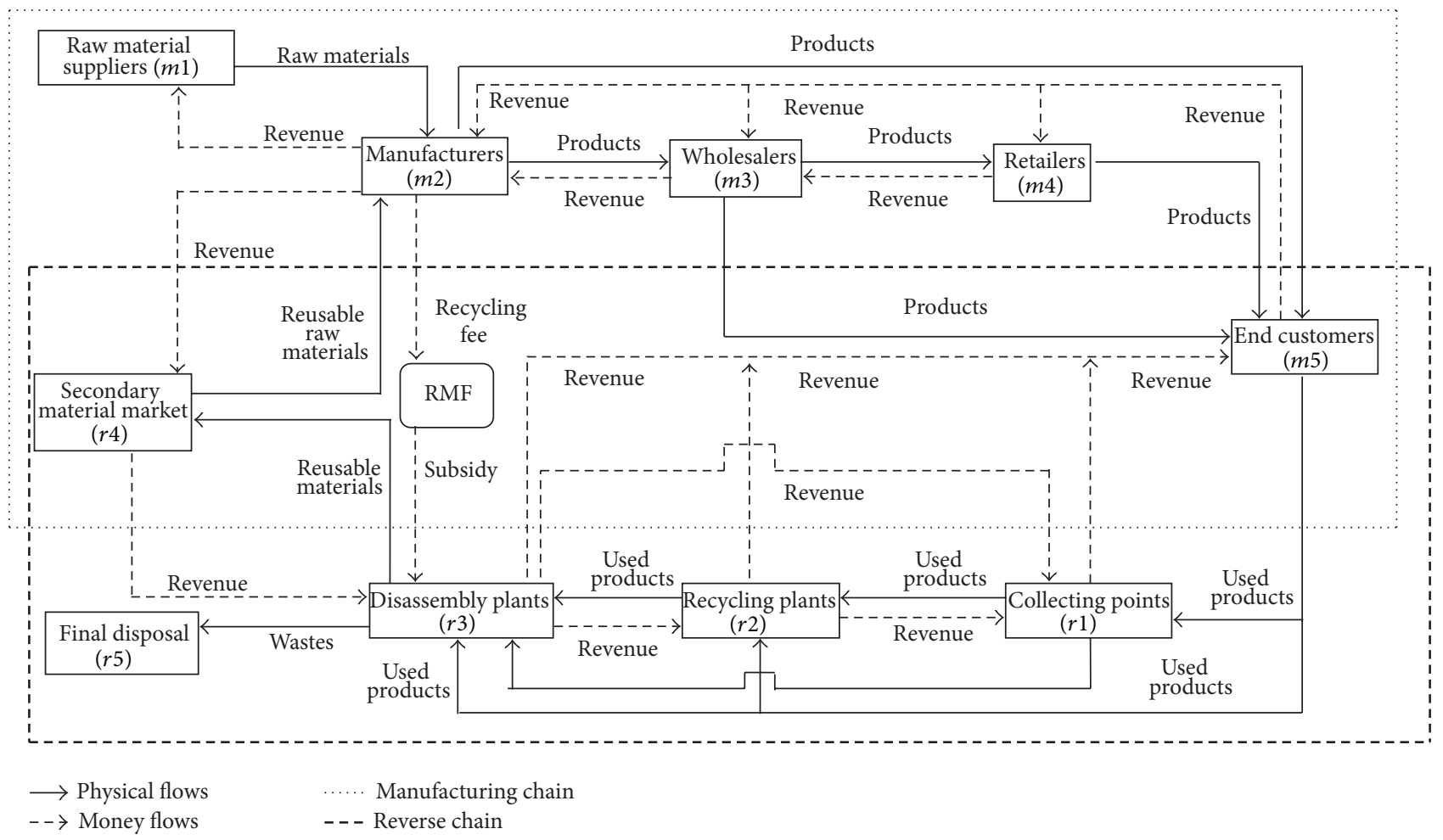

FIGURE 1: Conceptual framework for integrated logistics control across a green supply chain.

(8) Pollution such as heavy metal pollution, toxic pollution, and water pollution is not considered in this green supply chain.

A mathematical model was developed to seek equilibrium solutions with the target of maximizing the systematic net profit which aggregated from the chain-based net profits associated with the respect of the manufacturing supply chain and the reverse logistics chain. Figure 1 illustrates the conceptual framework for integrated logistics control across a green supply chain.

As we can see in Figure 1, there are two groups in the green supply chain system: (1) manufacturing supply chain and (2) used-product reverse supply chain. In addition, the typical 5-layer manufacturing supply chain is proposed; these layers are given as follows: raw material suppliers ( $m 1$ for short), manufacturers ( $m 2$ for short), wholesalers ( $m 3$ for short), retailers ( $m 4$ for short), and end customers ( $m 5$ for short). Also, the typical 5-layer used-product reverse supply chain is proposed as well with its layers given as follows: collecting points ( $r 1$ for short), recycling plants ( $r 2$ for short), disassembly plants ( $r 3$ for short), secondary material market ( $r 4$ for short), and final disposal ( $r 5$ for short). The mathematical formulation of our proposed model is indicated below. All notations of the proposed model are listed in the appendix.

3.2. Manufacturing Chain. According to the aforementioned assumptions, objective optimization models are formulated to seek the maximum net profit of the general supply chain and the reverse supply chain.
MP and RP are measured by subtracting the corresponding aggregate costs from the respective aggregate revenues and costs, as expressed, respectively, in (1) and (2) as follows:

$$
\begin{aligned}
\operatorname{Max} & \text { MP } \\
= & \text { MTR }- \text { MC }=\text { MTR } \\
& \quad(\text { MPC }+ \text { MMC }+ \text { MIC }+ \text { MTC }+ \text { MRC + MLC }) .
\end{aligned}
$$

As in (1), the total cost of manufacturing chain consists of six parts: raw material procurement, manufacturing, inventory, transportation, recycling fees paid to the EPA, and labor cost.

\subsection{Reverse Chain. Consider the following}

$\operatorname{Max} \mathrm{RP}=\mathrm{RTR}-\mathrm{RC}=(\mathrm{RR}+\mathrm{RS})$

$$
-(\mathrm{RTCC}+\mathrm{RTTC}+\mathrm{RIC}+\mathrm{RTC}+\mathrm{RFC}+\mathrm{RLC}) .
$$

Similarly, in (2), the total cost of the reverse chain is composed of six parts: the cost of collecting used products, transitional treatment, inventory, transportation, final disposal, and labor cost. Besides, there are two sources of revenue in the reverse chain: the general revenue and the subsidies from EPA.

From the proposed integrating logistics system architecture as shown in Figure 1, the objective functions are composed of (1) manufacturing chain-based net profit (MP) 
maximization and (2) reverse chain-based net profit (RP) maximization. And our target is to maximize the total revenue in the supply chain system as shown below:

$$
\begin{aligned}
\text { Max Total Revenue }= & \text { MP }+\mathrm{RP}=(\mathrm{MTR}-\mathrm{MC}) \\
& +(\mathrm{RTR}-\mathrm{RC}) .
\end{aligned}
$$

3.4. Revenues. $\mathrm{MTR}=$ Profit oriented from the raw material flows + Profit oriented from the physical flows of the manufactured product in any given distribution channel of the manufacturing chain:

$$
\begin{aligned}
\sum_{\forall t}\{ & {\left[\sum_{\forall m 1} \sum_{\forall m 2} R_{m 1, m 2}(t) \times Q_{m 1, m 2}(t)\right] } \\
+ & {\left.\left[\sum_{i=2}^{4} \sum_{i+1}^{5} \sum_{\forall m i} \sum_{\forall m j} R_{m i, m+1}(t) \times Q_{m i, m+1}(t)\right]\right\} . }
\end{aligned}
$$

$\mathrm{RR}=$ Refund obtained by end customer for returning the used product + Revenue associated with the used-product collection for selling the collected unprocessed used product to other reverse chains' members + Revenue from selling the processed used product to another member in the same reverse chain + Revenue of the secondary material market for selling the processed used raw materials to the layer of manufacturing of the given manufacturing chain:

$$
\begin{aligned}
\sum_{\forall t}\{[ & \left.\sum_{j=1}^{3} \sum_{\forall m 5} \sum_{\forall r j} R_{m 5, r j}(t) \times Q_{m 5, r j}(t)\right] \\
+ & {\left[\sum_{j=2}^{3} \sum_{\forall r 1} \sum_{\forall r j} R_{r 1, r j}(t) \times Q_{r 1, r j}(t)\right] } \\
+ & {\left[\sum_{j=2}^{3} \sum_{\forall r j} \sum_{\forall r j+1} R_{r j, r j+1}(t) \times Q_{r j, r j+1}(t)\right] } \\
+ & {\left.\left[\sum_{\forall r 4} \sum_{\forall m 2} R_{r 4, m 2}(t) \times Q_{r 4, m 2}(t)\right]\right\} . }
\end{aligned}
$$

RS $=$ Subsidies associated with the reverse chains that are oriented from the reverse flows of the returned used products transported to the layer of disassembly plants for government subsidies:

$$
\sum_{\forall t}\left\{\sum_{i=1}^{2} \sum_{\forall r i} \sum_{\forall r 3} \mathrm{EPO} \times Q_{r i, r 3}(t)\right\}
$$

As we mentioned in the earlier section, the revenues from manufacturing chain were composed of raw material and physical flows. And the revenues from the reverse chain were constituted of the regular returned used-product flows and subsidies.
3.5. Costs of Manufacturing Chain. The costs of manufacturing chain are composed of procurement, manufacturing, inventory, transportation, recycle, and labor cost. In this part, the detailed discussions of manufacturing chain are presented as follows.

MPC = Initialized cost of raw materials + Procurement cost oriented from raw material suppliers and secondary material market + Manufactured-product procurement costs in any distribution channels of manufacturing chain:

$$
\begin{aligned}
\sum_{\forall t}\left\{\left[\sum_{\forall m 1} C^{R}(t) \times Q^{R}(t)\right]\right. \\
+\left[\sum_{\forall m 1} \sum_{\forall m 2} C_{m 1, m 2}^{P}(t) \times Q_{m 1, m 2}(t)\right. \\
\left.+\sum_{\forall r 4} \sum_{\forall m 2} C_{r 4, m 2}^{P}(t) \times Q_{r 4, m 2}(t)\right] \\
\left.+\left[\sum_{i=2}^{3} \sum_{i+1}^{4} \sum_{\forall m i} \sum_{\forall m j} C_{m i, m i+1}^{P}(t) \times Q_{m i, m i+1}(t)\right]\right\} .
\end{aligned}
$$

MMC = Manufacturing cost of all manufactured products:

$$
\sum_{\forall t}\left\{\sum_{\forall m 2} C^{M}(t) \times Q^{M}(t)\right\} .
$$

MIC = Inventory cost of raw materials oriented from raw material suppliers and manufactures + Inventory cost of products in any chain member of the manufacturing chain:

$$
\sum_{\forall t}\left\{\left[\sum_{i=1}^{2} \sum_{\forall m i} C_{m i}^{\mathrm{IR}}(t) \times Q_{m i}^{\mathrm{IR}}(t)\right]+\left[\sum_{i=2}^{4} \sum_{\forall m i} C_{m i}^{I}(t) \times Q_{m i}^{I}(t)\right]\right\} .
$$

MTC $\cong$ Transportation cost of raw materials transported from suppliers to manufactures + Transportation cost of products transported in any chain member of the manufacturing chain:

$$
\begin{aligned}
\sum_{\forall t}\left\{\left[\sum_{\forall m 1} \sum_{\forall m 2}{\widetilde{C^{T}}}_{m 1, m 2}(t) \times Q_{m 1, m 2}(t)\right]\right. \\
\left.+\left[\sum_{i=2}^{4} \sum_{i+1}^{5} \sum_{\forall m i} \sum_{\forall m j}{\widetilde{C^{T}}}_{m i, m i+1}(t) \times Q_{m i, m i+1}(t)\right]\right\} .
\end{aligned}
$$

MRC $=$ Recycling fees of the products:

$$
\sum_{\forall t} \sum_{\forall m 2} F \times Q^{M}(t)
$$

MLC $=$ Labor cost of any member in the manufacturing chain:

$$
\sum_{\forall t}\left\{\sum_{i=1}^{4} \sum_{\forall m i} C_{m i}^{L} \times Q_{m i}^{L}(t)\right\}
$$


3.6. Costs of Reverse Chain. The costs of the reverse chain are composed of collected returned used products, transitional treatment procedures, inventory, transportation, final disposal, and labor cost. And we will discuss the reverse chain in this section.

RTCC $=$ The amount of used products collected from the end customer to the members of the reverse chain:

$$
\sum_{\forall t}\left\{\sum_{j=1}^{3} \sum_{\forall m 5} \sum_{\forall r j} C_{m 5, r j}^{C}(t) \times Q_{m 5, r j}(t)\right\} .
$$

RTTC $=$ The transitional treatment procedures executed potentially in all the reverse chain layers, except the final disposal:

$$
\sum_{\forall t}\left\{\sum_{j=1}^{4} \sum_{\forall r j} C_{r j}^{\mathrm{TT}}(t) \times Q_{r j}^{\mathrm{TT}}(t)\right\} .
$$

RIC $=$ The inventory cost of unprocessed used product + Inventory cost of processed used product + Inventory cost of processed used product that may be stored in disassembly plant which is for final disposal and selling to the secondary market:

$$
\begin{aligned}
\sum_{\forall t}\left\{\left[\sum_{j=1}^{4} \sum_{\forall r j} C_{r j}^{\overline{\mathrm{TT}}}(t) \times Q_{r j}^{\overline{\mathrm{T}}}(t)\right]\right. \\
+\left[\sum_{j=1, i \neq 3}^{4} \sum_{\forall r j} C_{r j}^{\mathrm{IT}}(t) \times C_{r j}^{\mathrm{IT}}(t)\right] \\
\left.\quad+\sum_{r 3}\left[C_{r 3, r 4}^{I}(t) \times Q_{r 3, r 4}^{I}(t)+C_{r 3, r 5}^{I}(t) \times Q_{r 3, r 5}^{I}(t)\right]\right\} .
\end{aligned}
$$

RTC $\cong$ The summation of transporting costs of any distribution channels of the reverse chain, excluding the collection costs that are oriented from the reverse flows associated with end customers:

$$
\begin{aligned}
\sum_{\forall t}\left\{\left[\sum_{j=2}^{3} \sum_{r 1} \sum_{\forall r j}{\widetilde{C^{T}}}_{r 1, r j}(t) \times Q_{r 1, r j}(t)\right]\right. \\
+\left[\sum_{i=2}^{3} \sum_{r i} \sum_{\forall r i+1}{\widetilde{C^{T}}}_{r i, r i+1}(t) \times Q_{r i, r i+1}(t)\right] \\
+\left[\sum_{\forall r 3} \sum_{\forall r 5} \widetilde{C^{T}}{ }_{r 3, r 5}(t) \times Q_{r 3, r 5}(t)\right] \\
\left.+\left[\sum_{\forall r 4} \sum_{\forall m 2} \widetilde{C^{T}}{ }_{r 4, m 2}(t) \times Q_{r 4, m 2}(t)\right]\right\} .
\end{aligned}
$$

RFC $=$ Total amount of used products disposed in the layer of final disposal:

$$
\sum_{\forall t}\left\{\sum_{\forall r 5} C^{F}(t) \times Q^{F}(t)\right\} .
$$

RLC $=$ Labor cost of any member in the reverse chain:

$$
\sum_{\forall t}\left\{\sum_{r=1}^{5} \sum_{\forall r j} C_{r j}^{L} \times Q_{r j}^{L}(t)\right\} .
$$

3.7. Constraints. In this part, the detailed discussions of three constraints such as inventory constraints, demand constraints, and return resource constraints are presented as follows.

(i) Inventory Constraints. In order to reach the reality, we set safety stock for every member in the two chains.

(a) For raw material suppliers,

$$
\begin{aligned}
S S_{m 1}^{\mathrm{IR}} \leq & Q_{m 1}^{\mathrm{IR}}(t)=Q_{m 1}^{\mathrm{IR}}(t-1)+Q^{R}(t) \\
& -\sum_{\forall m 2} Q_{m 1, m 2}(t) \leq S_{m 1}^{\mathrm{IR}} \quad \forall(m 1, t) .
\end{aligned}
$$

(b) For product manufacturers,

(1) for raw materials,

$$
\begin{aligned}
S S_{m 2}^{\mathrm{IR}} \leq & Q_{m 2}^{\mathrm{IR}}(t)=Q_{m 2}^{\mathrm{IR}}(t-1) \\
& +\left[\sum_{\forall m 1} Q_{m 1, m 2}(t)+\sum_{\forall r 4} Q_{r 4, m 2}(t)\right] \\
& -\gamma_{m 2}^{r / m} \times Q^{M}(t) \leq S_{m 2}^{\mathrm{IR}} \quad \forall(m 2, t),
\end{aligned}
$$

(2) for products,

$$
\begin{aligned}
S S_{m 2}^{I} \leq & Q_{m 2}^{I}(t)=Q_{m 2}^{I}(t-1)+Q^{M}(t) \\
& -\sum_{j=3}^{5} \sum_{\forall m j} Q_{m 2, m j}(t) \leq S_{m 2}^{I} \quad \forall(m 2, t) .
\end{aligned}
$$

(c) For wholesalers and retailers,

$$
\begin{aligned}
S S_{m j}^{I} \leq & Q_{m j}^{I}(t)=Q_{m j}^{I}(t-1) \\
& +\left[\sum_{i=2}^{j-1} \sum_{\forall m i} Q_{m i, m j}(t)\right]-\left[\sum_{n=j+1}^{5} \sum_{\forall m n} Q_{m j, m n}(t)\right] \\
\leq & S_{m j}^{I} \quad \forall(m j, t), j=3 \text { or } 4 .
\end{aligned}
$$

(d) For collecting points,

$$
\begin{aligned}
S S_{r 1}^{\overline{\mathrm{TT}}} \leq & Q_{r 1}^{\overline{\mathrm{IT}}}(t)=Q_{r 1}^{\overline{\mathrm{TT}}}(t-1)+\left[\sum_{\forall m 5} Q_{m 5, r 1}(t)\right] \\
& -Q_{r 1}^{\mathrm{TT}}(t) \leq S_{r 1}^{\overline{\mathrm{TT}}} \quad \forall(r 1, t), \\
S S_{r 1}^{\mathrm{IT}} \leq & Q_{r 1}^{\mathrm{IT}}(t)=Q_{r 1}^{\mathrm{IT}}(t-1)+Q_{r 1}^{\mathrm{TT}}(t) \\
& -\sum_{j=2}^{3} \sum_{\forall r j} Q_{r 1, r j}(t) \leq S_{r 1}^{\mathrm{IT}} \quad \forall(r 1, t) .
\end{aligned}
$$


(e) For recycle plants,

$$
\begin{aligned}
S S_{r 2}^{\overline{\mathrm{TT}}} \leq & Q_{r 2}^{\overline{\mathrm{IT}}}(t)=Q_{r 2}^{\overline{\mathrm{IT}}}(t-1) \\
& +\left[\sum_{\forall m 5} Q_{m 5, r 2}(t)+\sum_{\forall r 1} Q_{r 1, r 2}(t)\right] \\
& -Q_{r 2}^{\mathrm{TT}}(t) \leq S_{r 2}^{\overline{\mathrm{TT}}} \quad \forall(r 2, t), \\
S S_{r 2}^{\mathrm{IT}} \leq & Q_{r 2}^{\mathrm{IT}}(t)=Q_{r 2}^{\mathrm{IT}}(t-1)+Q_{r 2}^{\mathrm{TT}}(t) \\
& -\sum_{\forall r 3} Q_{r 2, r 3}(t) \leq S_{r 2}^{\mathrm{IT}} \quad \forall(r 2, t) .
\end{aligned}
$$

(f) For disassembly plants,

$$
\begin{aligned}
S S_{r 3}^{\overline{\mathrm{TT}}} \leq & Q_{r 3}^{\overline{\mathrm{IT}}}(t)=Q_{r 3}^{\overline{\mathrm{IT}}}(t-1) \\
& +\left[\sum_{\forall m 5} Q_{m 5, r 3}(t)+\sum_{i=1}^{2} \sum_{\forall r i} Q_{r i, r 3}(t)\right] \\
& -Q_{r 3}^{\mathrm{TT}}(t) \leq S_{r 3}^{\overline{\mathrm{IT}}} \quad \forall(r 3, t), \\
S S_{r 3, r 4}^{\mathrm{IT}} \leq & Q_{r 3, r 4}^{I}(t)=Q_{r 3, r 4}^{I}(t-1)+\gamma_{r 3, r 4} \quad \forall(r 3, t), \\
& \times Q_{r 3}^{\mathrm{TT}}(t)-\sum_{\forall r 4} Q_{r 3, r 4}(t) \leq S_{r 3, r 4}^{I} \quad \forall(t)=\gamma_{r 3, r 5}^{I} \quad \forall(r 3, t) . \\
S S_{r 3, r 5}^{I} \leq & Q_{r 3, r 5}^{I}(t)=S_{r 3, r 5}^{I}(t-1) \quad \\
& \times Q_{r 3}^{\mathrm{TT}}(t)-\sum_{\forall r 5} Q_{r 3, r 5}(t) \leq S_{r 3, r 5} \quad \forall(r)
\end{aligned}
$$

(g) For secondary material markets,

$$
\begin{aligned}
S S_{r 4}^{\overline{\mathrm{IT}}} \leq & Q_{r 4}^{\overline{\mathrm{IT}}}(t)=Q_{r 4}^{\overline{\mathrm{IT}}}(t-1)+\left[\sum_{\forall r 3} Q_{r 3, r 4}(t)\right] \\
& -Q_{r 4}^{\mathrm{TT}}(t) \leq S_{r 4}^{\overline{\mathrm{IT}}} \quad \forall(r 4, t), \\
S S_{r 4}^{\mathrm{IT}} \leq & Q_{r 4}^{\mathrm{IT}}(t)=Q_{r 4}^{\mathrm{IT}}(t-1)+\gamma_{t 4}^{t r e} \times Q t_{r r 4}(t) \\
& -\sum_{\forall m 2} Q_{r 4, m 2}(t) \leq S_{r 4}^{\mathrm{IT}} \quad \forall(r 4, t) .
\end{aligned}
$$

(h) For final disposal locations,

$$
\begin{aligned}
S S_{r 5}^{\overline{\mathrm{IT}}} \leq & Q_{r 5}^{\overline{\mathrm{IT}}}(t)=Q_{r 5}^{\overline{\mathrm{IT}}}(t-1)+\left[\sum_{\forall r 3} Q_{r 3, r 5}(t)\right] \\
& -Q_{r 5}^{F}(t) \leq S_{r 5}^{\overline{\mathrm{IT}}} \quad \forall(r 5, t) .
\end{aligned}
$$

(ii) Demand Constraints. Consider the following

$$
\widetilde{D(t)} \geq \sum_{i=2}^{4} \sum_{\forall m i} \sum_{\forall m 5} Q_{m i, m 5}(t) \geq 0 \quad \forall t .
$$

(iii) Return Resource Constraints. Consider the following

$$
Q^{\mathrm{RE}}(t)=\sum_{j=1}^{3} \sum_{\forall m 5} \sum_{\forall r j} Q_{m 5, r j}(t)=\beta \times \widetilde{D(t)} \geq 0 \quad \forall t .
$$

\section{Treatment of the Fuzzy Formulation}

In practice, Liang [30] noted that decision-makers are more familiar with estimating optimistic, pessimistic, and most likely parameters. The pattern of triangular distribution is commonly adopted due to ease in defining the maximum and minimum limit of deviation of the fuzzy number of its central value. Furthermore, according to the definition of Rommelfanger [31], when knowledge of the distribution is limited, triangular distribution is appropriate for representing a fuzzy number. And then, other studies also indicated that the primary advantages of the triangular fuzzy number are the simplicity and flexibility of the fuzzy arithmetic operations [31-35].

In order to discuss the fuzziness of the integrated logistics model for the demand and transportation cost, there are some definitions stated as follows [34].

Definition 1. The fuzzy set $\widetilde{B}=(a, b, c)$, where $a<b<c$ is defined on $R$, is called the triangular fuzzy number, if the membership function of $\widetilde{B}$ is given by

$$
\mu_{\widetilde{B}}(x)= \begin{cases}\frac{(x-a)}{(b-a)}, & a \leq x \leq b, \\ \frac{(c-x)}{(c-b)}, & b \leq x \leq c, \\ 0, & \text { otherwise. }\end{cases}
$$

Definition 2. The fuzzy set $\left[a_{\alpha}, b_{\alpha}\right]$ defined on $R, 0 \leq \alpha \leq 1$, is called an $\alpha$-level fuzzy interval if the membership function of $\left[a_{\alpha}, b_{\alpha}\right]$ is given by

$$
\mu_{\left[a_{\alpha}, b_{\alpha}\right]}(x)= \begin{cases}\alpha, & a \leq x \leq b \\ 0, & \text { otherwise }\end{cases}
$$

Definition 3. Let $\widetilde{B}$ be a fuzzy set on $R$, and $0 \leq \alpha \leq 1$; then the $\alpha$-cut, $B(\alpha)$, of $\widetilde{B}$ consists of points $x$ such that $\mu_{\widetilde{B}}(x) \geq \alpha$; that is, $B(\alpha)=\left\{x \mid \mu_{\widetilde{B}}(x) \geq \alpha\right\}$.

With (10) and (15), if the minimum acceptable membership level $\alpha$ is given, the corresponding auxiliary crisp inequality expression of these two equations can be presented as follows:

$$
\begin{aligned}
\mathrm{MTC} \cong \sum_{\forall t}\{[ & w 1 \sum_{\forall m 1} \sum_{\forall m 2} \widetilde{C t}_{m 1, m 2}^{p, \alpha}(t) \times Q_{m 1, m 2}(t) \\
& +w 2 \sum_{\forall m 1} \sum_{\forall m 2} \widetilde{C t}_{m 1, m 2}^{m, \alpha}(t) \times Q_{m 1, m 2}(t) \\
& \left.+w 3 \sum_{\forall m 1} \sum_{\forall m 2} \widetilde{C t}_{m 1, m 2}^{o, \alpha}(t) \times Q_{m 1, m 2}(t)\right]
\end{aligned}
$$




$$
\begin{aligned}
& +\left[w 1 \sum_{i=2}^{4} \sum_{j=i+1}^{5} \sum_{\forall m i} \sum_{\forall m j} \widetilde{C t}_{m i, m j}^{p, \alpha}(t) \times Q_{m i, m j}(t)\right. \\
& +w 2 \sum_{i=2}^{4} \sum_{j=i+1}^{5} \sum_{\forall m i} \sum_{\forall m j} \widetilde{C t}_{m i, m j}^{m, \alpha}(t) \times Q_{m i, m j}(t) \\
& \left.\left.+w 3 \sum_{i=2}^{4} \sum_{j=i+1}^{5} \sum_{\forall m i} \sum_{\forall m j} \widetilde{C t}_{m i, m j}^{o, \alpha}(t) Q_{m i, m j}(t)\right]\right\}, \\
& \mathrm{RTC} \cong \sum_{\forall t}\left\{\left[w 1 \sum_{j=2}^{3} \sum_{r 1} \sum_{\forall r j} \widetilde{C t}_{m i, m j}^{p, \alpha}(t) \times Q_{r 1, r j}(t)\right.\right. \\
& +w 2 \sum_{j=2}^{3} \sum_{r 1} \sum_{\forall r j} \widetilde{C t}_{m i, m j}^{m, \alpha}(t) \times Q_{r 1, r j}(t) \\
& \left.+w 3 \sum_{j=2}^{3} \sum_{r 1} \sum_{\forall r j} \widetilde{C t}_{m i, m j}^{o, \alpha}(t) \times Q_{r 1, r j}(t)\right] \\
& +\left[w 1 \sum_{i=2}^{3} \sum_{r i} \sum_{\forall r i+1} \widetilde{C t}_{r i, r i+1}^{p, \alpha}(t) \times Q_{r i, r i+1}(t)\right. \\
& +w 2 \sum_{i=2}^{3} \sum_{r i} \sum_{\forall r i+1} \widetilde{C t}_{r i, r i+1}^{m, \alpha}(t) \times Q_{r i, r i+1}(t) \\
& \left.+w 3 \sum_{i=2}^{3} \sum_{r i} \sum_{\forall r i+1} \widetilde{C t}_{r i, r i+1}^{o, \alpha}(t) \times Q_{r i, r i+1}(t)\right] \\
& +\left[w 1 \sum_{\forall r 3} \sum_{\forall r 5} \widetilde{C t}_{r 3, r 5}^{p, \alpha}(t) \times Q_{r 3, r 5}(t)\right. \\
& +w 2 \sum_{\forall r 3} \sum_{\forall r 5} \widetilde{C t}_{r 3, r 5}^{m, \alpha}(t) \times Q_{r 3, r 5}(t) \\
& \left.+w 3 \sum_{\forall r 3} \sum_{\forall r 5} \widetilde{C t}_{r 3, r 5}^{o, \alpha}(t) \times Q_{r 3, r 5}(t)\right] \\
& +\left[w 1 \sum_{\forall r 4} \sum_{\forall m 2} \widetilde{C t}_{r 4, m 2}^{p, \alpha}(t) \times Q_{r 4, m 2}(t)\right. \\
& +w 2 \sum_{\forall r 4} \sum_{\forall m 2} \widetilde{C t}_{r 4, m 2}^{m, \alpha}(t) \times Q_{r 4, m 2}(t) \\
& \left.\left.+w 3 \sum_{\forall r 4} \sum_{\forall m 2} \widetilde{C t}_{r 4, m 2}^{o, \alpha}(t) \times Q_{r 4, m 2}(t)\right]\right\} .
\end{aligned}
$$

Similarly, if the minimum acceptable membership level $\alpha$ is given, the constraint of demand is presented as follows:

$$
\begin{gathered}
w 1 \widetilde{D(t)}^{p, \alpha}+w 2 \widetilde{D(t)}^{m, \alpha}+w 3 \widetilde{D(t)}^{o, \alpha} \\
\geq \sum_{i=2}^{4} \sum_{\forall m i} \sum_{\forall m 5} Q_{m i, m 5}(t) \geq 0 \quad \forall t .
\end{gathered}
$$

The weights of $w 1, w 2$, and $w 3(w 1+w 2+w 3=1)$ must represent the weight of the most pessimistic, most likely, and most optimistic values of the fuzzy variables. We set $w 2=$ $4 / 6, w 1=w 3=1 / 6$, and $\alpha=0.5$ for all formulations. However, in reality, the value $\alpha$ and the relative weightings among three critical points can be adjusted subjectively based on the experience and knowledge of decision-makers and/or experts. The most likely values are used here because they are generally the most important ones and, thus, should be assigned greater weights [30]. However, the most pessimistic and most optimistic values which provided the boundary solutions of fuzzy market demand for each destination are too pessimistic and optimistic, respectively, and, thus, should be assigned smaller weights [35].

For convenience, we will use fuzzy summation calculation (FSC) to integrate all the experts' optimistic, most likely and pessimistic estimation values into one value, respectively. If $A$ is a parameter and $A^{p}, A^{m}$, and $A^{o}$ represent the fuzzy number of $A$ 's optimistic, most likely and pessimistic estimation values. The formulation of integration is given as follows $[36,37]$ :

$$
\begin{aligned}
& A^{p}=\min \left\{A_{k}^{p}\right\}, \\
& A^{m}=\min \left\{A_{k}^{m}\right\}, \\
& A^{o}=\max \left\{A_{k}^{o}\right\} .
\end{aligned}
$$

\subsection{Solving Procedure}

Step 1. Based on (1) (27), we formulate the original fuzzy multiobjective linear programming model for the integrated logistic problems.

Step 2. Based on (32) and (33), we provide the acceptable minimum membership level $\alpha$ and then convert the fuzzy inequality constraints into crisp ones using the weighted average method.

Step 3. This step is to integrate all optimistic, most likely and pessimistic estimation values into one value, respectively, according to (34).

Step 4. Final step is to solve the ordinary LP problem. If the DM is dissatisfied with the initial solutions, the model should be adjusted until a preferred satisfactory solution is obtained.

\section{Numerical Result}

To illustrate the effectiveness of the models presented above, we examine a simplified numerical study. Sheu et al. [29] have conducted a local operational case of a well-known Taiwanese notebook computer manufacturer which is one of the top three domestic brands in Taiwan. This case study is based on the logistics distribution channels and built a simplified integrated logistics network of the given notebook manufacturers in the northern region of Taiwan. The collected historical and interview survey data were used to estimate both the input data such as annual sales and used-product returns and primary parameters like logistics-induced operational 
TABLE 1: Estimates of unit revenues.

\begin{tabular}{lc}
\hline Layer & Unit revenue (US\$) \\
\hline \multicolumn{2}{c}{ Manufacturing chain } \\
(1) Raw material supplier & 42 \\
(2) Manufacturer & 485 \\
(3) Wholesaler & 673 \\
(4) Retailer & 873 \\
(5) End customer & 2.5 \\
\hline & \\
(1) Collecting point & Reverse chain \\
(2) Recycle plant & 5.55 \\
(3) Disassembly plant & 7.8 \\
(4) Secondary material market & 10.85 \\
Subsidy & 22.5 \\
\hline
\end{tabular}

TABLE 2: Estimates of manufacturing chain unit costs.

\begin{tabular}{lcc}
\hline Layer & Parameter & Unit cost (US\$) \\
\hline \multirow{3}{*}{ (1) Raw material supplier } & $C^{R}$ & 19.5 \\
& $C_{m 1}^{\mathrm{IR}}$ & 1.75 \\
& $C_{m 1}^{L}$ & 5 \\
\hline & $C_{m 1, m 2}^{P}$ & 24 \\
& $C_{r 4, m 2}^{P}$ & 22.5 \\
(2) Manufacturer & $C^{M}$ & 115 \\
& $C_{m 2}^{I}$ & 69.5 \\
& $C_{m 2}^{\mathrm{IR}}$ & 50 \\
& $C_{m 2}^{L}$ & 5 \\
\hline \multirow{3}{*}{ (3) Wholesaler } & $C_{m 2, m 3}^{P}$ & 531.5 \\
& $C_{m 3}^{I}$ & 86.5 \\
& $C_{m 3}^{L}$ & 5 \\
\hline \multirow{3}{*}{ (4) Retailer } & $C_{m 3, m 4}^{P}$ & 621.5 \\
& $C_{m 4}^{I}$ & 101.5 \\
& $C_{m 4}^{L}$ & 5 \\
\hline
\end{tabular}

costs for use in formulating the integrated logistics management problem. With fuzzy formulations, the decisionmaker can consider the environment under variable demand and transportation cost which are more close to the real. Details of the primary procedures in the numerical study and corresponding results are presented below.

5.1. Parameter Settings. Based on Sheu et al. [29], the parameters will be used as the average of Sheu's data as shown in Tables 1, 2, 3, and 4 .

Because demand and transportation cost were fuzzy numbers, these were conducted with high-level decisionmakers of the targeted notebook manufacturing enterprise and its potential channel members, including the chain members in both the manufacturing and the reverse chains. These parameters will be estimated as optimistic, pessimistic, and most likely numbers and will be integrated by using the center of gravity method.

We invited five experts to estimate the demand and transportation cost, while the last column is the data after
TABLE 3: Estimates of used-product reverse chain unit costs.

\begin{tabular}{lcc}
\hline Layer & Parameter & Unit cost (US\$) \\
\hline & $C_{m 5, r 1}^{C}$ & 1 \\
(1) Collecting point & $C^{\mathrm{TT}}$ & 6.5 \\
& $C^{\overline{\mathrm{IT}}}$ & 0.45 \\
& $C^{\mathrm{IT}}$ & 0.45 \\
& $C_{r 1}^{L}$ & 3.5 \\
\hline \multirow{3}{*}{ (2) Recycle plant } & $C_{m 5, r 2}^{C}$ & 1.85 \\
& $C^{\mathrm{TT}}$ & 2.85 \\
& $C^{\overline{\mathrm{IT}}}$ & 0.45 \\
& $C^{\mathrm{IT}}$ & 0.45 \\
& $C_{r 2}^{L}$ & 3.5 \\
\hline \multirow{3}{*}{ (3) Disassembly plant } & $C_{m 5, r 3}^{C}$ & 2.15 \\
& $C^{\mathrm{TT}}$ & 1.75 \\
& $C^{\overline{\mathrm{IT}}}$ & 0.45 \\
& $C_{r 3, r 4}^{I}$ & 1.8 \\
& $C_{r 3, r 5}^{I}$ & 0.23 \\
& $C_{r 3}^{L}$ & 3.5 \\
\hline & $C_{r 3, r 4}^{C}$ & 4.4 \\
& $C^{\mathrm{TT}}$ & 2.05 \\
& $C^{\overline{\mathrm{IT}}}$ & 1.05 \\
& $C^{\mathrm{IT}}$ & 1.6 \\
& $C_{r 4}^{L}$ & 3.5 \\
\hline
\end{tabular}

integrating into one number through fuzzy summation calculation [36, 37]. In addition, Table 5 shows the other parameters of the model.

In convenience, the initial inventory condition of each member in the manufacturing and the reverse chains was generated here using a respective uniform distribution bounded by the range between 0 and the corresponding inventory capacity estimated.

5.2. Results. According to the corresponding regulations of the Taiwan EPA for 2005, the unit subsidy is set to be 10 (US\$). The numerical results are summarized in Table 6.

Table 6 indicates the maximum profit of the manufacturing chain and the reverse chain. When we aggregate manufacturing and reverse chains together, there will be some factors influencing each other, so the maximum aggregate profit is not the combination of the single profit of each chain.

Accordingly, manufacturers can be convinced more easily to coordinate all the chain members for the promotion of GSCM. In addition, subsidy strategies also have a strong impact on reverse logistics chain system. Due to the above mentions, we take the unit subsidy into further investigation. In practice, the unit subsidy may rely on the corresponding environmental protection regulations imposed by the EPA [29].

Figure 2 shows the sensitivity analysis of the unit subsidy parameter to investigate the potential effects of these parameters on the performance of the reverse logistics chain.

In Figure 2, when the governmental subsidy value increased. This indicates that the governmental subsidy 
TABLE 4: Inventory capacity.

(a) Manufacturing chain

\begin{tabular}{lcccc}
\hline$S_{m 1}^{\mathrm{IR}}$ & $S_{m 2}^{\mathrm{IR}}$ & $S_{m 2}^{I}$ & $S_{m 3}^{I}$ & $S_{m 4}^{I}$ \\
\hline 7000 & 5000 & 5000 & 500 & 100 \\
\hline$S S_{m 1}^{\mathrm{IR}}$ & $S S_{m 2}^{\mathrm{IR}}$ & $S S_{m 2}^{I}$ & $S S_{m 3}^{I}$ & $S S_{m 4}^{I}$ \\
\hline 3500 & 2500 & 2500 & 250 & 50 \\
\hline
\end{tabular}

(b) Reverse chain

\begin{tabular}{|c|c|c|c|c|c|c|c|c|c|}
\hline$\overline{S_{r 1}^{\overline{I T}}}$ & $S_{r 1}^{I T}$ & $\overline{S_{r 2}^{\overline{T T}}}$ & $S_{r 2}^{I T}$ & $\overline{S_{r 3}^{\bar{T}}}$ & $S_{r 3, r 4}^{I}$ & $S_{r 3, r 5}^{I}$ & $\overline{S_{r 4}^{\overline{T T}}}$ & $S_{r 4}^{\mathrm{IT}}$ & $\overline{S_{r 5}^{\overline{\Gamma T}}}$ \\
\hline 500 & 500 & 1000 & 1000 & 2500 & 1500 & 500 & 1000 & 800 & 500 \\
\hline$S S_{r 1}^{\overline{T T}}$ & $S S_{r 1}^{\mathrm{IT}}$ & $S S_{r 2}^{\overline{I T}}$ & $S S_{r 2}^{\mathrm{IT}}$ & $S S_{r 3}^{\overline{I T}}$ & $S S_{r 3, r 4}^{I}$ & $S S_{r 3, r 5}^{I}$ & $S S_{r 4}^{\overline{I T}}$ & $S S_{r 4}^{\mathrm{IT}}$ & $S S_{r 5}^{\overline{\bar{T}}}$ \\
\hline 250 & 250 & 500 & 500 & 1200 & 750 & 250 & 500 & 400 & 250 \\
\hline
\end{tabular}

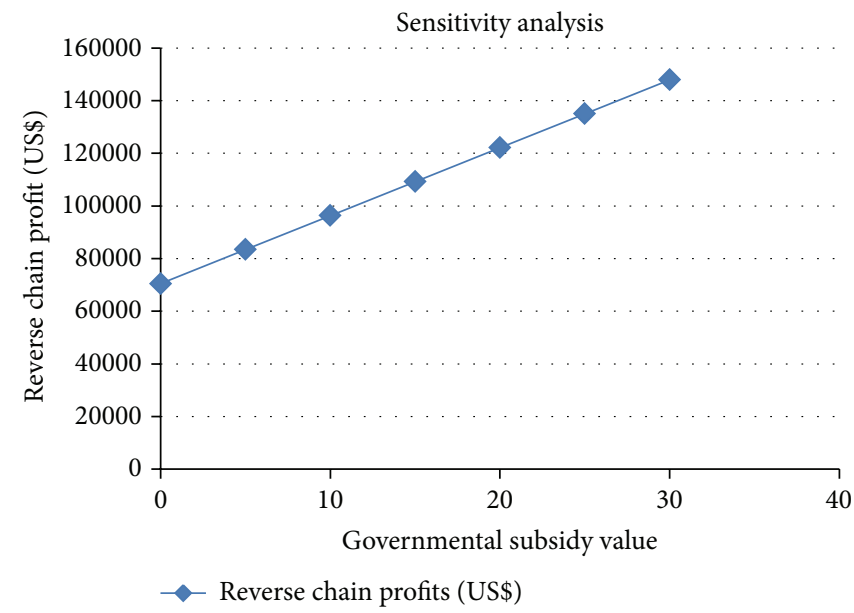

FIGURE 2: Numerical result of sensitivity analysis.

TABLE 5: Other parameters.

\begin{tabular}{lc}
\hline Return ratio $(\beta)$ & 0.25 \\
Unit recycle fee $(F)$ & 1.1 \\
Unit subsidy $(S)$ & 10 \\
Used-product return & 1538 \\
\hline
\end{tabular}

TABLE 6: Numerical result.

\begin{tabular}{lc}
\hline & Net profit (US\$) \\
\hline Manufacturing chain & $5,399,846$ \\
Reverse chain & 96,308 \\
Aggregate & $5,454,023$ \\
\hline
\end{tabular}

policy remains as a critical determinant in influencing the performance of used-product reverse chain.

\section{Conclusion}

With the encouragement of environmental consciousness recently, the issue of environmental protection has been becoming a trend of supply chain management. In addition, the enterprises also have to take more applicable measures to improve the reverse logistics. Therefore, we formulated a fuzzy multiobjective integrated logistics model which coordinated the cross-functional product logistics flows and used-product reverse logistics flows with green supply chain consideration.

The findings of the numerical result indicated that the maximum profit is $\$ 5,399,846$ in the manufacturing chain and $\$ 96,308$ in the reverse chain. And the results showed that the maximum profit was up to $\$ 5,454,023$ when we aggregated these two chains together. In addition, we found that when the governmental subsidy value increased, the profit of the reverse chain also increased, the profit of the reverse chain also increased. The findings of this study identified that the governmental subsidy policy could remain of significant influence for used-product reverse logistics chain.

Nevertheless, this paper is not totally without merit. We are hopeful that our experimental results are of great interest for both application and scientific research. Most importantly, we will make every endeavor to cooperate with more realworld cases to acquire more perusable and actual data as our future works. Finally, the future research might usefully extend the present use of the proposed models to examine 
TABle 7: Notations for our proposed model.

\begin{tabular}{|c|c|}
\hline \multicolumn{2}{|r|}{ Manufacturing chain cost } \\
\hline MC & Total cost \\
\hline MIC & Total inventory cost \\
\hline MMC & Total manufacturing cost \\
\hline MPC & Total raw material procurement cost \\
\hline MTC & Total transportation cost \\
\hline MRC & Total recycling fees paid from the manufacturing layer of a given manufacturing chain to the corresponding EPA \\
\hline MLC & Labor cost \\
\hline \multicolumn{2}{|r|}{ Manufacturing chain revenue } \\
\hline MTR & Total revenue \\
\hline \multicolumn{2}{|r|}{ Reverse chain cost } \\
\hline $\mathrm{RC}$ & Total cost \\
\hline RTCC & Total collection cost of corresponding used products \\
\hline RFC & Total final disposal cost of corresponding used products \\
\hline RIC & Total inventory cost \\
\hline RTC & Total transportation cost \\
\hline RTTC & Total transitional treatment cost of the corresponding used products \\
\hline RLC & Labor cost \\
\hline \multicolumn{2}{|r|}{ Reverse chain revenue } \\
\hline RTR & Total revenue \\
\hline $\mathrm{RR}$ & Total revenue oriented specifically from general vendor-buyer business operations \\
\hline RS & Total subsidies \\
\hline \multicolumn{2}{|r|}{ Revenue } \\
\hline$R_{m i / m i+1}$ & $\begin{array}{l}\text { The generalized revenues from layer } i \text { of the given manufacturing chain to layer } i+1 \text { of the given manufacturing chain } \\
(i=2,3,4)\end{array}$ \\
\hline$R_{m 5 / r j}$ & $\begin{array}{l}\text { The generalized revenues from end customers in layer } 5 \text { of the given manufacturing chain to layer } j \text { of the given reverse chain } \\
(j=1,2,3)\end{array}$ \\
\hline$R_{r 1 / r j}$ & $\begin{array}{l}\text { The generalized revenues from the collecting points in layer } 1 \text { of the given reverse chain to layer } j \text { of the given reverse chain } \\
(j=2,3)\end{array}$ \\
\hline$R_{r j / r j+1}$ & The generalized revenues from layer $j$ of the given reverse chain to layer $j+1$ of the given reverse chain $(j=2,3)$ \\
\hline$R_{r 4 / m 2}$ & $\begin{array}{l}\text { The generalized revenues from the second material market in layer } 4 \text { of the given reverse chain to the manufactures in layer } 2 \\
\text { of the given manufacturing chain }\end{array}$ \\
\hline EPO & The unit subsidy of environmental protection offered by EPA \\
\hline \multicolumn{2}{|r|}{ Cost } \\
\hline$C^{C}$ & Collecting cost of used product returned from end customer \\
\hline$C^{I}$ & Inventory cost for storing products \\
\hline$C^{\mathrm{IR}}$ & Inventory cost for storing raw materials \\
\hline $\mathrm{C}^{\mathrm{IT}}$ & Inventory cost for storing used product that has been treated by a reverse logistics chain member \\
\hline$C^{\overline{\mathrm{TT}}}$ & Inventory cost for storing used product that has not been treated by a reverse logistics chain member \\
\hline$C^{M}$ & Manufacturing cost of used product \\
\hline$C^{P}$ & Procurement cost of physical flow $i$ \\
\hline$\widetilde{C^{T}}$ & Transportation cost \\
\hline$C^{\mathrm{TT}}$ & Transitional treatment cost \\
\hline$F$ & Recycling fees charged by the corresponding EPA for manufacturing products \\
\hline$C^{F}$ & Unit cost of final disposal \\
\hline$C^{L}$ & Hourly labor cost \\
\hline$C^{R}$ & Raw material cost \\
\hline
\end{tabular}


TABLe 7: Continued.

\begin{tabular}{|c|c|}
\hline \multicolumn{2}{|r|}{ Quantity } \\
\hline$Q^{I}$ & Quantity of inventory-decision variable \\
\hline$Q^{\mathrm{IR}}$ & Quantity of raw materials inventory_decision variable \\
\hline$Q^{\mathrm{IT}}$ & Quantity of inventory of used product that has been treated \\
\hline$Q^{\overline{\Gamma T}}$ & Quantity of inventory of used product that has not been treated invent \\
\hline$Q^{F}$ & Quantity of final disposal_-decision variable \\
\hline$Q^{M}$ & Manufacturing quantity_decision variable \\
\hline$Q^{R}$ & Raw materials quantity_-decision variable \\
\hline$Q^{\mathrm{TT}}$ & Transitional treatment quantity-decision variable \\
\hline$Q^{\mathrm{RE}}$ & Quantity of used product that has been returned by end customers \\
\hline$Q^{L}$ & Quantity of labors-decision variable \\
\hline$Q_{m i, m 5}$ & $\begin{array}{l}\text { The generalized form of a decision variable referring to the physical flow quantity transported from layer } i \text { given in the } \\
\text { manufacturing chain to end customers in layer } 5 \text { given in the manufacturing chain }(i=2,3,4)\end{array}$ \\
\hline$Q_{m i, m i+1}$ & $\begin{array}{l}\text { The generalized form of a decision variable referring to the physical flow quantity transported from layer } i \text { given in the } \\
\text { manufacturing chain to layer } i+1 \text { given in the manufacturing chain }(i=1,2,3,4)\end{array}$ \\
\hline$Q_{m 5, r j}$ & $\begin{array}{l}\text { The generalized form of a decision variable referring to the physical flow quantity transported from end customers in layer } 5 \\
\text { given in the manufacturing chain to layer } j \text { given in the reverse chain }(j=1,2,3)\end{array}$ \\
\hline$Q_{r 1, r 2}$ & $\begin{array}{l}\text { The generalized form of a decision variable referring to the physical flow quantity transported from collecting points in layer } 1 \\
\text { of the given reverse chain to recycling plants in layer } 2 \text { given in the reverse chain }\end{array}$ \\
\hline$Q_{r 1, r 3}$ & $\begin{array}{l}\text { The generalized form of a decision variable referring to the physical flow quantity transported from collecting points in layer } 1 \\
\text { of the given reverse chain to disassembly plants in layer } 3 \text { given in the reverse chain }\end{array}$ \\
\hline$Q_{r 2, r 3}$ & $\begin{array}{l}\text { The generalized form of a decision variable referring to the physical flow quantity transported from recycling plants in layer } 2 \\
\text { given in the reverse chain to disassembly plants in layer } 3 \text { of the given reverse chain }\end{array}$ \\
\hline$Q_{r 3, r 4}$ & $\begin{array}{l}\text { The generalized form of a decision variable referring to the physical flow quantity transported from disassembly plants in } \\
\text { layer } 3 \text { of the given reverse chain to final disposal in layer } 4 \text { given in the reverse chain }\end{array}$ \\
\hline$Q_{r 3, r 5}$ & $\begin{array}{l}\text { The generalized form of a decision variable referring to the physical flow quantity transported from disassembly plants in } \\
\text { layer } 3 \text { given in the reverse chain to final disposal in layer } 5 \text { of the given reverse chain }\end{array}$ \\
\hline$Q_{r 5, m 2}$ & $\begin{array}{l}\text { The generalized form of a decision variable referring to the physical flow quantity transported from final disposal in layer } 5 \text { of } \\
\text { the given reverse chain to manufactures in layer } 2 \text { given in the manufacturing chain }\end{array}$ \\
\hline \multicolumn{2}{|r|}{ Facility capacity } \\
\hline$S$ & Safety stock \\
\hline$S^{I}$ & Facility capacity for inventory \\
\hline$S^{\mathrm{IR}}$ & Facility capacity for raw material inventory \\
\hline$S^{\mathrm{IT}}$ & Facility capacity for inventory that has already been treated \\
\hline$S^{\overline{\mathrm{TT}}}$ & Facility capacity for inventory that has not been treated \\
\hline \multicolumn{2}{|r|}{ Others } \\
\hline$\beta$ & Predetermined used-product return ratio \\
\hline$\gamma$ & A coefficient referring to the transformation \\
\hline$\widetilde{D}$ & Demand of manufacturing chain end customer \\
\hline
\end{tabular}

more green supply chain management aspects and solve more GSCM-related problems.

\section{Appendix}

See Table 7.

\section{Conflict of Interests}

The authors declare that there is no conflict of interests regarding the publication of this paper.

\section{Acknowledgments}

This paper was supported by the National Science Committee of Taiwan under Grant no. NSC 100-2410-H-019-004. Also, the authors wish to thank the referees for those comments which provide a great help for authors to consider their research more deeply.

\section{References}

[1] L. Abdel-Malek, T. Kullpattaranirun, and S. Nanthavanij, "A framework for comparing outsourcing strategies in multilayered supply chains," International Journal of Production Economics, vol. 97, no. 3, pp. 318-328, 2005.

[2] R. Narasimhan and J. R. Carter, Environmental Supply Chain Management, The Center for Advanced Purchasing Studies, Arizona State University, Tempe, Ariz, USA, 1998.

[3] D. Petrovic, R. Roy, and R. Petrovic, "Supply chain modelling using fuzzy sets," International Journal of Production Economics, vol. 59, no. 1-3, pp. 443-453, 1999. 
[4] I. Giannoccaro, P. Pontrandolfo, and B. Scozzi, "A fuzzy echelon approach for inventory management in supply chains," European Journal of Operational Research, vol. 149, no. 1, pp. 185-196, 2003.

[5] J. Drzymalski and N. G. Odrey, "Supervisory control of a multi-echelon supply chain: a modular Petri net approach for inter-organizational control," Robotics \& Computer-Integrated Manufacturing, vol. 24, no. 6, pp. 728-734, 2008.

[6] A. T. Gumus and A. F. Guneri, "A multi-echelon inventory management framework for stochastic and fuzzy supply chains," Expert Systems with Applications, vol. 36, no. 3, part 1, pp. 5565$5575,2009$.

[7] R. Ganeshan, "Managing supply chain inventories: a multiple retailer, one warehouse, multiple supplier model," International Journal of Production Economics, vol. 59, no. 1-3, pp. 341-354, 1999.

[8] H. Rau, M. Wu, and H. Wee, "Integrated inventory model for deteriorating items under a multi-echelon supply chain environment," International Journal of Production Economics, vol. 86, no. 2, pp. 155-168, 2003.

[9] A. J. Clark and H. Scarf, "Optimal policies for a multi-echelon inventory problem," Management Science, vol. 6, no. 4, pp. 475590,1960

[10] S. Elhedhli and F. Gzara, "Integrated design of supply chain networks with three echelons, multiple commodities and technology selection," IIE Transactions, vol. 40, no. 1, pp. 31-44, 2008 .

[11] S. M. Disney, M. Lambrecht, D. R. Towill, and W. van de Velde, "The value of coordination in a two-echelon supply chain," IIE Transactions, vol. 40, no. 3, pp. 341-355, 2008.

[12] Ö. Yazlali and F. Erhun, "Dual-supply inventory problem with capacity limits on order sizes and unrestricted ordering costs," IIE Transactions, vol. 41, no. 8, pp. 716-729, 2009.

[13] M. Pagell, C. L. Yang, D. W. Krumwiede, and C. Sheu, "Does the competitive environment influence the efficacy of investment in environmental management?" Journal of Supply Chain Management, vol. 40, no. 3, pp. 30-39, 2004.

[14] S. Wang, L. Zhang, Z. Liu, G. Liu, and H. C. Zhang, "Study on the performance assessment of green supply chain," in Proceedings of the IEEE International Conference on Systems, Man and Cybernetics, vol. 1, pp. 942-947, October 2005.

[15] C.-W. Hsu, T.-C. Kuo, S.-H. Chen, and A. H. Hu, "Using DEMATEL to develop a carbon management model of supplier selection in green supply chain management," Journal of Cleaner Production, vol. 56, pp. 164-172, 2013.

[16] M. S. Pishvaee, S. A. Torabi, and J. Razmi, "Credibility-based fuzzy mathematical programming model for green logistics design under uncertainty," Computers \& Industrial Engineering, vol. 62, no. 2, pp. 624-632, 2012.

[17] A. J. C. Trappey, C. V. Trappey, C. T. Hsiao, J. J. R. Ou, and C. T. Chang, "System dynamics modelling of product carbon footprint life cycles for collaborative green supply chains," International Journal of Computer Integrated Manufacturing, vol. 25, no. 10, pp. 934-945, 2012.

[18] R. E. Bellman and L. A. Zadeh, "Decision-making in a fuzzy environment," Management Science, vol. 17, pp. B141-B164, 1970.

[19] H. J. Zimmermann, "Description \& optimization of fuzzy systems," International Journal of General Systems, vol. 2, no. 4, pp. 209-215, 1976.

[20] H.-J. Zimmermann, "Fuzzy programming and linear programming with several objective functions," Fuzzy Sets and Systems, vol. 1, no. 1, pp. 45-55, 1978.
[21] C. C. Li, Y. P. Fun, and J. S. Hung, "A new measure for supplier performance evaluation," IIE Transactions on Operations Engineering, vol. 29, no. 9, pp. 753-758, 1997.

[22] M. Kumar, P. Vrat, and R. Shankar, "A fuzzy goal programming approach for vendor selection problem in a supply chain," Computers \& Industrial Engineering, vol. 46, no. 1, pp. 69-85, 2004.

[23] M. Kumar, P. Vrat, and R. Shankar, "A fuzzy programming approach for vendor selection problem in a supply chain," International Journal of Production Economics, vol. 101, no. 2, pp. 273-285, 2006.

[24] A. Amid, S. H. Ghodsypour, and C. O'Brien, "Fuzzy multiobjective linear model for supplier selection in a supply chain," International Journal of Production Economics, vol. 104, no. 2, pp. 394-407, 2006.

[25] H. Leberling, "On finding compromise solutions in multicriteria problems using the fuzzy min-operator," Fuzzy Sets and Systems, vol. 6, no. 2, pp. 105-118, 1981.

[26] E. L. Hannan, "Linear programming with multiple fuzzy goals," Fuzzy Sets and Systems, vol. 6, no. 3, pp. 235-248, 1981.

[27] M. Sakawa and H. Yano, "An interactive fuzzy satisficing method for multiobjective linear fractional programming problems," Fuzzy Sets and Systems, vol. 28, no. 2, pp. 129-144, 1988.

[28] M. K. Luhandjula, "Compensatory operators in fuzzy linear programming with multiple objectives," Fuzzy Sets and Systems, vol. 8, no. 3, pp. 245-252, 1982.

[29] J.-B. Sheu, Y.-H. Chou, and C.-C. Hu, "An integrated logistics operational model for green-supply chain management," Transportation Research E: Logistics and Transportation Review, vol. 41, no. 4, pp. 287-313, 2005.

[30] T.-F. Liang, "Fuzzy multi-objective production/distribution planning decisions with multi-product and multi-time period in a supply chain," Computers \& Industrial Engineering, vol. 55, no. 3, pp. 676-694, 2008.

[31] H. Rommelfanger, "Fuzzy linear programming and applications," European Journal of Operational Research, vol. 92, no. 3, pp. 512-527, 1996.

[32] J. J. Buckley, "Possibilistic linear programming with triangular fuzzy numbers," Fuzzy Sets and Systems, vol. 26, no. 1, pp. 135$138,1988$.

[33] H. Tanaka, P. Guo, and I. B. Türksen, "Portfolio selection based on fuzzy probabilities and possibility distributions," Fuzzy Sets and Systems, vol. 111, no. 3, pp. 387-397, 2000.

[34] J. C.-H. Pan and M.-F. Yang, "Integrated inventory models with fuzzy annual demand and fuzzy production rate in a supply chain," International Journal of Production Research, vol. 46, no. 3, pp. 753-770, 2008.

[35] R. C. Wang and T. F. Liang, "Applying possibilistic linear programming to aggregate production planning," International Journal of Production Economics, vol. 98, no. 3, pp. 328-341, 2005.

[36] C. Y. Chiu, C. L. Meng, and M. F. Yang, "Comprehensive high school learning group selection model using fuzzy set theory," Educational Research \& Information, vol. 10, no. 4, pp. 67-84, 2002.

[37] R. Elliott and A. C. Strenta, "Effects of improving the reliability of the gpa on prediction generally \& on comparative predictions for gender \& race particularly," Journal of Education Measurement, vol. 25, pp. 333-347, 1998. 


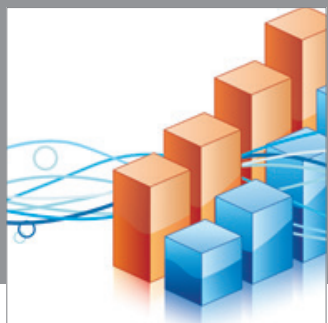

Advances in

Operations Research

mansans

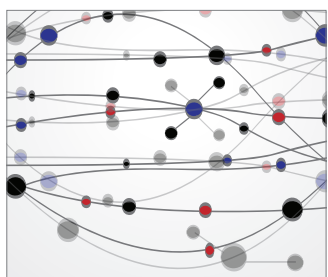

The Scientific World Journal
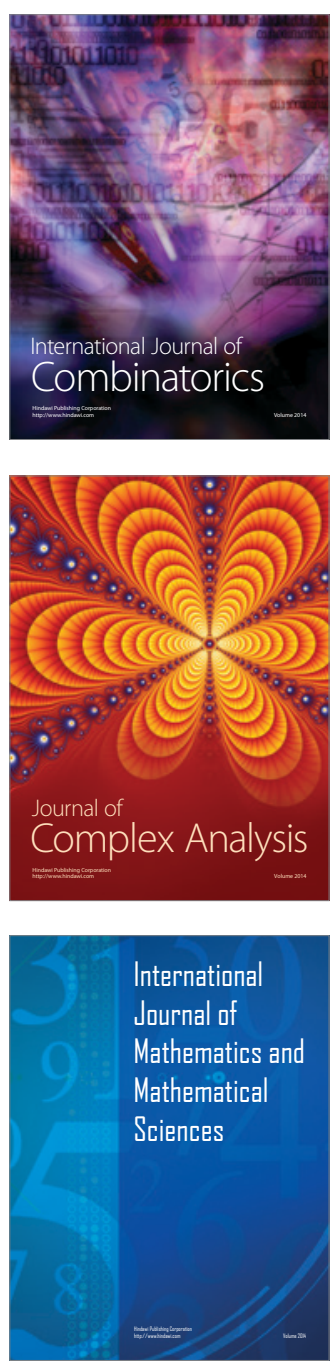
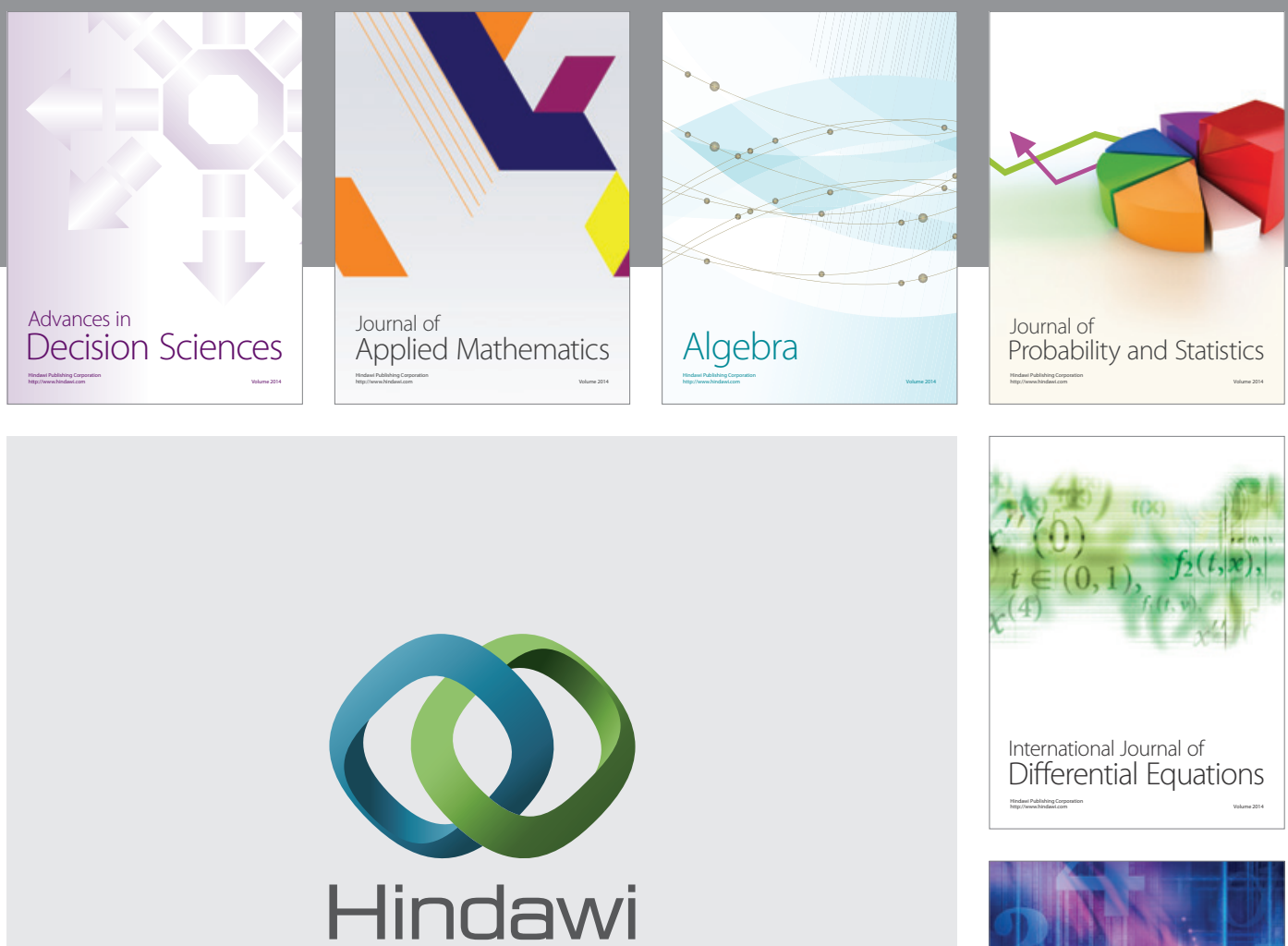

Submit your manuscripts at http://www.hindawi.com
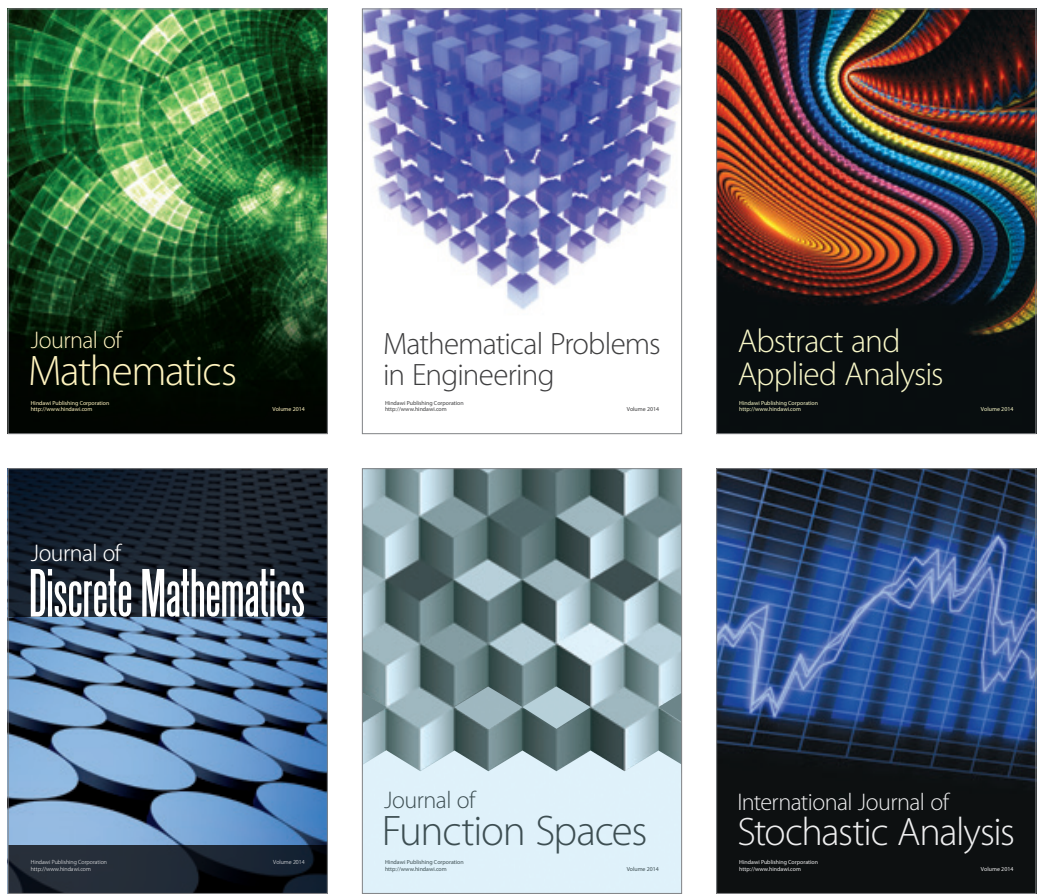

Journal of

Function Spaces

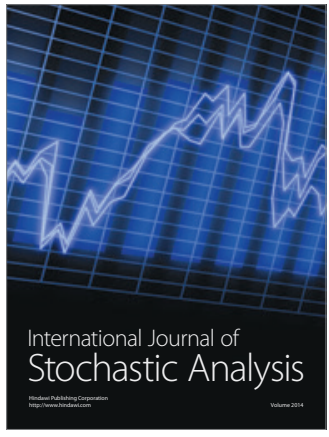

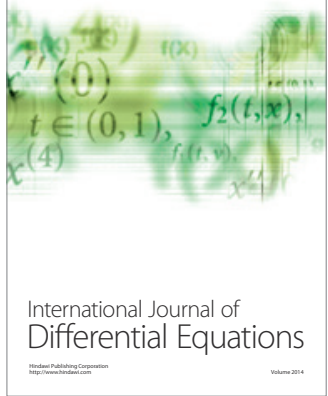
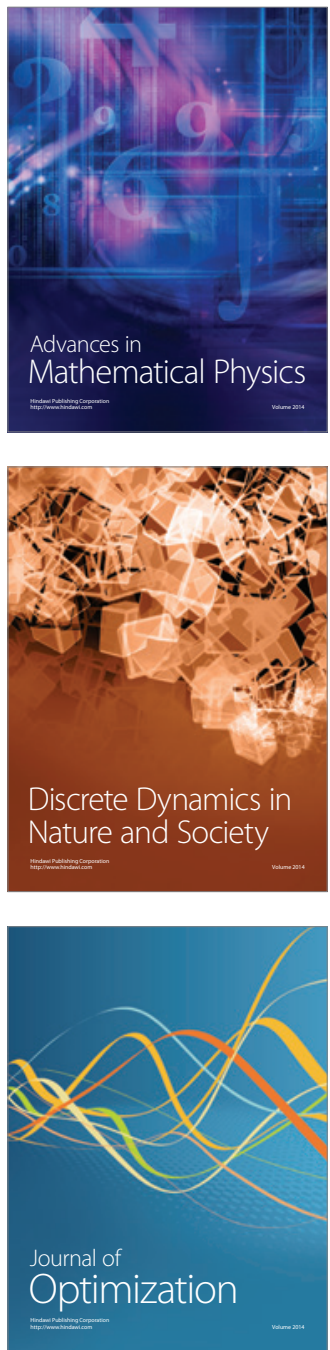